\title{
THE BOROUGH OF KIMBERLEY.
}

\author{
By JAMES S. DUNN.
}

Borough Sanitary Inspector.

(Associa TE.)

$\mathrm{W}^{\mathrm{n}}$ ITHOUT going into past history, it would be unfair to describe the existing sanitary arrangements of a young colonial mining town, such as Kimberley, to a body of up-to-date sanitarians at home, many of whom hare probably never left their native shores, and perhaps can hardly realize a sudden rush for wealth far into the interior of a wild country; the undeliberated formation of a camp, quickly reaching the dimensions of a town, and populated at first with a people anxious to make their pile and clear. I would therefore ask you to bear with me while I tell you something of the Kimberley of thirty years ago; after which we will follow its sanitary progress until we have ascertained its condition to-day.

Kimberley dates from the year 1870, when diamonds were first discovered on the farms of Du Toits Pan and Hultfontein. It is about 650 miles from Cape Town, and 4,042 feet above sea level.

Much information regarding Kimberley in its early days and up to the year 1882 is given in a book written by Dr. J. W. Matthews, late VicePresident of the Legislative Council of South Africa, and late senior Member for Kimberley in the Cape House of Assembly, and entitled "Incwadi Yami; or, Twenty Years' Personal Experience in South Africa."

Dr. Matthews also writes: "No more wretched existence can be imagined than that endured by the early diggers. A malarial fever raged, water was dear and bad, being carted in barrels from adjacent farms(even after wells were dug it was sold for as much as 10s. per barrel)and so scarce that I have seen diggers wash in soda water which had been imported 700 miles from Capetown. Vegetables were also extremely dear and almost unprocurable, cauliflowers being retailed at 20s. each, and cabbages at $8 \mathrm{~s}$. Fleas and flies abounded, sand storms blew in blind fury, and of amusements there were none; yet notwithstanding all these drawbacks sociability ruled throughout the camps, and a helping hand was always thrown out by a lucky digger to assist his less fortumate brother." 
The municipality was created in 1878 , and, in the following year Dr. Matthews assisted in the preparation of a report on the sanitary condition of the borough, for the Mayor and Town Council. The death-rate at that time was enormous, being 40.005 per thousand for Europeans, and 79.052 per thousand for the coloured classes. At that time Kimberley was perfectly honeycombed with cesspools, and attention was drawn to the evil effects of the existing system and to the manner in which these had revealed themselves two years before, when an epidemic of puerperal fever and erysipelas had robbed the community of many valuable lives, and it was also shown that there was always existing a remittent fever of a dysenteric and typhoid tendency, which could in some measure be attributed to this defective sanitary condition. The report led to the adoption of the "Pail System", the night soil being taken away regularly and buried some distance from the town. The death-rate from clisease was soon diminished by one-third.

In 1882 small-pox broke out in the vicinity of Cape Town, haring been imported by the ill-fated steamship "Drummond Castle," about 4,000 succumbing to its ravages. Great apprehension was felt in Kimberley, lest the disease might be communicated by the passenger wagons coming up from Cape Town, and a quarantine station was immediately established at the Modder River, with the result that seven cases of small-pox were detected and detained for treatment, and all others travelling by the same wagons were quarantined for twenty-one days. These efforts were entirely successful, for not one single case of small-pox broke out in Kimberley, but the threatened invasion put the ratepayers to an expense of nearly $£ 13,000$.

The following year small-pox again broke out in South Africa; this time amongst some Kaffirs who were travelling to Kimberley from the Transvaal. The total number of cases reported during this period was 2,311 and the number of deaths $700,(30 \cdot 29$ per cent.), the proportion of white cases against coloured was very marked, the number of white being 400 with 51 deaths ( 12.07 per cent.), and of coloured 1,911 with 649 deaths (33.96 per cent.).

The most striking feature of Kimberley to-day is the irregularity with which the town is laid out, due undoubtedly to its growth from a mining camp. The buildings in the past were constructed chiefly of corrugated iron, but latterly many substantial edifices have been erected. The principal buildings are the Town Hall erected at a cost of about $£ 18,000$ and opened just before the outbreak of the recent war; the Government Offices; the Post and Telegraph Offices; the Public Library; the 


\section{Notes on Sanitary Conditions in South Africa.-Kimberley.}

Kimberley Club; the Masonic Temple; the Sanatorium and the Synagogue, just near completion the cost of which will be $£ 15,000$. The population is nearly 30,000, of whom about 13,000 are of European extraction. The climate is very salubrious; the changes of temperature are sudden and great, but the excessive dryness of the soil and atmosphere enables the residents to withstand with but little inconvenience a heat which would be quite unbearable in a moist climate. The rainfall is about 18 ins. per annum; in 1878 it was $9 \cdot 34$, in 1881 it was $30 \cdot 30$.

So far back as 1889, the Borough Council of Kimberley were seriously ronsidering the introduction of a sewerage system for the town. In that year Messirs. Pritchard \& Co. of London prepared an excellent report dealing with the removal of night soil and all waste waters, and treating them on a piece of land outside. But the high price of water was evidently the fatal objection to the plan: 1s. 3d. per 100 gals. was and is the price still charged. On the abandonment af Messrs. Pritchard's scheme serious attention was given to the construction of a slop-water sewer in order to lessen the cost of cartage on the removal of same; the year 1898 saw the completion of this work which was carried out in conjunction with a municipal wash-house. The total length of the sewer, which is of 9 -in. stoneware pipe, is $2,870 \mathrm{yds}$; it has one intake consisting of an underground chamber with a siphon. The slop carts discharge their contents on to a grating, 10 feet square. Manholes occur at all deviations and provision is made for ventilation. About 28,000 gals. of slop-water are daily carted to and discharged into this sewer which in its turn discharges same on to a piece of land, let out for cultivating purposes; this has been yielding good crops.

The municipal wash-house, already referred to, was considered absolutely necessary owing to the manner in which public washing was carried on in various parts of the town, the dirty water being thrown about surreptitiously either on to streets or private stands. The desirability of the establishment of a site in a convenient position, and the erection of a building with the necessary appliances, including of course the provision of an ample water supply and a satisfactory method of disposing of the waste water, was referred to a special committee appointed by the Council in 1897, and resulted in this much needed improvement being effected. The building consists of an open shed $72 \mathrm{ft}$. long by $30 \mathrm{ft}$. wide, divided up into 24 compartments; two tubs are allotted to each compartment with water fittings and trapped waste pipes, a drying ground adjoins and the whole site is properly enclosed. Perhaps at some future date ironing rooms will be added. The wash-house is run at a considerable 
loss to the Council but the reduction to a minimum of nuisances from slop water in certain parts of the town is considered the greatest benefit to be derived from the building.

The removal of night soil is carried out on the "Duplicate Pail System." The work is performed by contract, short term prisoners being let ont by the Government for this purpose at 6d. per diem. Removals are effected three times a week, clean disinfected pails being substituted in lieu of those removed. The present contract expires at the end of this rear and in arranging the new contract the Council are endeavouring to effect removals erery forty-eight hours continuously; this alteration will necessitate Sunday labour but the importance of frequent removals is recognised as more important than anything else. An important feature in connection with our pail removal service is the vehicle used for conveying the night-soil out of the town; this was an innovation with the present contract. Instead of the usual van for receiving the full buckets, the Kimberley vehicle consists of a tank mounted on wheels into which the buckets are emptied direct; the capacity of the tank is $600 \mathrm{gals}$, and the contents are discharged by means of a valve underneath. There is a box-like arrangement in front for storing the empty buckets. Oxen or donkeys are employed for their haulage. For transport purposes in Soutl Africa with our rough roads this vehicle is far superior to the old fashioned rans, from which, unless the buckets are provided with tight fitting lids, a disgusting trail is frequently left along the roads traversed by the rans. The night soil is deposited into trenches about three miles from the town; no attempt is made to utilize it in any way. Five shillings per month per bucket is the fixed charge for removals.

The remoral of rubbish until about three years ago, when the Council undertook the work departmentally, was effected by private enterprise; proceedings were instituted against occupiers when large accunulations were discovered on their premises. Last year, however, this work with the removal of slop water was let out to contract. Rubbish removals are effected weekly, a montlily charge being made, depending either upon the size of the house or its ratable value. Special arrangements are made for hotels, \&c. At present the rubbish is removed out of town by rail to a tip about three miles away, but in May of this year an agreement was entered into between the Council and the Pyrojom Syndicate of London for the conversion of the towns refuse into fuel.

The removal of slop water by carts is a laborious, costly, and unsatisfactory process. No slop water is permitted to flow in the thoroughfares, and upon the discovery of nuisances arising from its disposal upon any premises 
immediate action is taken. With the exception of the slop-water sewer previously referred to, there is not an underground drain of any sort in Kimberley; this is satisfactory in some respects, for in the consileration of a comprehensive scheme for the town, we shall not be hampered in any way with existing and possibly doubtful sewers. The Comcil are now considering the question of extending the slop-water drain to the centre of the town for the convenience of the principal buildings and hotels, but all work done will be with a view to its ultimately forming part of a permanent scheme.

A location for natives is situated outside the township; the population is about 7,000, and it is still extending. It is surveyed ont into streets and building plots, 10 s. per quarter being the rent charged. The water supply is from thirteen wells which belong to the Council, and for the use of which a charge of 2s. 6d. per quarter is made. The sanitary arrangements are not perfect at the present time, the latrines consisting of trenches, with wood and iron screens, at various spots outsicle and about 100 yards from the huts. In a few months, however, a suitable sanitary service will probably be established and worked on similar lines to the towns service, but with daily removals of the night soil. Rubbish is not allowed to accumulate; it is deposited outside and burned. Many of the huts are well built, and the conditions under which the inhabitants live are superior to the existence of those who reside in certain parts of the town. The location is controlled in an orderly manner by a superintendent with a staff of native constables; it is healthily situated, and has been remarkably free from sickness. It is satisfactory to be able to record that not a single case of plague broke out during the recent severe epidemic in Cape Colony.

In 1895 a report on the sanitary condition of Kimberley was presented to the Council by Dr. Geo. Turner, the then Medical Officer of Health to the Government. He estimated the death-rate at $15 \cdot 1$ per thousand for Europeans and 33.7 per thousand for natives. In 1898 the death-rate was 21.7 per thousand for Europeans and 54.9 for natives; whilst the infantile mortality of children under one year of age was 197 per thousand for whites and 467 for the coloured classes.

A comparison of the death returns for the years 1899 and 1900 is given in the following table, showing the increased mortality during the period the town was besieged:-

Taking everything into consideration, Kimberley will bear very favourable comparison with any other town in the Colony as regards its sanitary condition. Practically no slums exist; but in certain parts of the town natives and Asiatics do live under conditions which are not satisfactory. 


\begin{tabular}{c|c|c|c|c}
\multicolumn{3}{|c|}{ Denth-rate per 1000. } & \multicolumn{2}{c}{ For First 9 months, before Siege. } \\
\hline 1899. & Whites. & Coloured. & Whites. & Coloured. \\
& 24.6 & $53 \cdot 1$ & 17.0 & 4.9 \\
\hline 1900. & $24 \cdot 6$ & 883 & For Last 9 months, after Siege. \\
\hline
\end{tabular}

INFANTILE MORTALITY.

Deaths of Children under One Year of Age:

\begin{tabular}{|c|c|c|c|c|}
\hline \multicolumn{3}{|c|}{ Death-rnte per 100 Born. } & \multicolumn{2}{|c|}{ For First 9 months, beiore Siege. } \\
\hline \multirow[t]{2}{*}{1899.} & $\begin{array}{l}\text { Whites. } \\
212 \cdot 8\end{array}$ & $\begin{array}{l}\text { Coloured. } \\
462 \cdot 5\end{array}$ & $\begin{array}{l}\text { Whites, } \\
152 \cdot 0\end{array}$ & $\begin{array}{c}\text { Coloured. } \\
386 \cdot 2\end{array}$ \\
\hline & & & \multicolumn{2}{|c|}{ Excluding First 3 montlus. } \\
\hline 1900. & $2(13.9$ & $622 \cdot 9$ & $151: 3$ & $5+1 \cdot 2$ \\
\hline
\end{tabular}

They have to huddle together in close, confined quarters; and in dealing with them there are sometimes prejudices to overcome which render the task exceedingly difficult.

The Borough Council is not backward in considering and adopting any practical improvements brought to its notice. In the comrse of a few years the control of the waterworks will be in the hands of the towns people; this will probably materially assist in the solution of the sewernge problem. Many circumstances in the past have interfered with the consideration of municipal undertakings, such as periods of commercial depression, the unsettled state of the country from time to time, unforseen expenditure in other directions, \&c. The revenue of the Council is

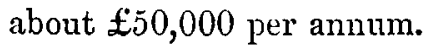

